\title{
CHARACTERIZATION OF LOCAL AND EXOTIC SUGARCANE GENOTYPES ON THE BASIS OF MORPHOLOGICAL AND QUALITY RELATED ATTRIBUTES
}

\author{
Sundas Shahzad ${ }^{1,2,}$, Farooq Ahmad Khan ${ }^{1}$, Muhammad Zafar Iqbal'2, Ihsan Khaliq1 \\ and Nisar Ahmed ${ }^{3}$ \\ ${ }^{1}$ Department of Plant Breeding and Genetics, University of Agriculture, Faisalabad, Pakistan; ${ }^{2}$ Agricultural \\ Biotechnology Research Institute, AARI, Faisalabad, Pakistan; ${ }^{3}$ Centre of Agricultural Biochemistry and \\ Biotechnology, University of Agriculture, Faisalabad, Pakistan. \\ "Corresponding author's e-mail: sundas.shahzad@yahoo.com
}

\begin{abstract}
The current breeding program of sugarcane in Pakistan does not fulfill the variety evolution of desired characters. It mostly depends on import of exotic fuzz-seed of sugarcane varieties, without keeping varietal characters in view. So, it is the dire need of the time to characterize the sugarcane germplasm not only for saving resources but also for finding genetic relationships among breeding materials for overall sugarcane crop improvement. In the present study 60 genotypes of sugarcane, belonged to 3 research stations two of Pakistan and one from Sri Lanka, were characterized using Principal Component Analysis (PCA) and Cluster Analysis. At maturity data were analyzed for 19 traits and analyzed. PCA showed seven principal components (PCs) having eigen value more than one and exhibited $72.1 \%$ variability in the genotypes. Four groups of PCA were formed for the traits. Cluster analysis placed genotypes in seven groups. Groups were not formed according to origins of genotypes which might be due to resemblance in their progenitors. Each cluster was also marked for specific trait improvement related to that cluster based upon maximum mean value of that trait, either through selection or hybridization. Four traits were found better in Sugarcane Research Institute, Faisalabad (SRI, FSD) genotypes, five in Shakarganj Sugarcane Research Institute (SSRI), Jhang genotypes and three in Sugarcane Research Institute (SRI), Udawalawae, Sri Lankan genotypes, on the basis of mean values. Thus more emphasis could be given on these traits related to specific station for use in variety selection program for improvement of target trait. Another interesting conclusion drawn from the study was that clusters were not formed according to genotypes of a specific research station because these local and exotic sugarcane genotypes are allopolyploid (with aneuploidy) hybrids, and can be traced back to founder clones (S. officinarum $\times$ S. spontaneum ).
\end{abstract}

Keywords: Sugarcane, breeding, morphology, PCA, clustering, genetic diversity.

\section{INTRODUCTION}

Sugarcane (Saccharum spp. hybrids) is grown in many countries of the world like other agricultural crops for different purposes. Human and animal needs such as food, feed and fuel are being satisfied by this crop (D'Hont et al., 1998). Sugar and its by-products like ethanol, molasses, bagasse, press mud and wax etc. are derived from this non cereal grass which is widely cultivated in tropical and subtropical regions of the world. It recently has attained particular consideration as a second generation energy crop for cellulosic ethanol due to its high-biomass (Pinto et al., 2010; Suman et al., 2011). It is an important cash crop of Pakistan, mainly grown for sugar and sugar-related products like Gur and Shakr. Keeping in view the prominent position of sugarcane in the agricultural industry, strenuous efforts are being made for the improvement of this crop for sustainable and better agronomic traits (Nawaz et al., 2013). So, for fulfilling the needs of ever increasing population it is crucial to increase sugar yield of this crop.
Sugar yield is a quantitative character and depends upon cane yield and sugar recovery. Considering the constraints (latitude, diurnal temperature, humidity and photo period), for true seed (fuzz) production of sugarcane in the country the chances of genetic improvement through conventional breeding only are very low. Assessment of genetic diversity is very important for the improvement of sugarcane because diverse parents could be crossed by breeders for producing viable superiors (Hamrick 2004). Sugarcane breeding has thrived all over the world largely by intercrossing the original inter-specific hybrids and their derived progenies. Genetic diversity in cultivated sugarcane is alarmingly narrow (Berding and Roach, 1987) because only a few clones were involved in the original crosses (Irvine 1999). In Pakistan new varieties of sugarcane are mostly evolved through selection. The selection procedure can be strengthen to many folds if the scientists are well aware with the genetic makeup of parentage used. Mostafa et al. (2011) described that an understanding of genetic diversity for finding genetic associations among 
populations, makes the heterogeneous groups of specific lines.

Different statistical techniques have been used including Principal Component Analysis (PCA) and Cluster Analysis by Ward's method for characterization of genotypes and same were successfully practiced in sugarcane (Olaoye 1999; Luo et al., 2005; Ilyas, 2011; Klomsa et al., 2013; Brasileiro et al., 2013; Tahir et al., 2013; You et al., 2013), rice (Ogunbayo et al., 2005), cotton (Rana et al., 2005) and bread wheat (Khodadadi et al., 2011; Fahim 2014).

Therefore, the present study was undertaken for grouping of parents and various traits in order to use in future breeding program keeping in view the region-wise specific traits of genotypes.

\section{MATERIALS AND METHODS}

The germplasm used in the present study were obtained from SRI, FSD having 31 genotypes including series: Canal Point (CP), Sao Paulo (SP), Hawaii (H) and Barbados (B); SSRI, Jhang having 15 genotypes including series: Sao Paulo (SP), Canal Point (CP), CSIRO, Australia (CS) and Hauma (Ho) and SRI, Udawalawae, Sri Lanka having 14 genotypes including series: Philippine (PH), Coimbatore (Co), Mauritius (M) and North Carolina (NC) in their progenitors (Table 1).

Double budded setts of 60 sugarcane genotypes were planted to raise the crop at experimental field, at latitude $30-35^{\circ}$ to $31-$ $47^{\circ}$ North and $72-80^{\circ}$ to $73-40^{\circ}$ East longitude, of Sugarcane Research Institute, Ayub Agricultural Research Institute (AARI), Faisalabad-Pakistan, on loamy soil having $\mathrm{pH}$ of 7.8, EC (0.36 dsm-1) and organic matter of 0.90 (\%). Sixty genotypes were planted in randomized complete block design with 3 replications. Three rows ( 5 meters long) for each genotype were maintained with a row to row distance of $60 \mathrm{~cm}$ and plant to plant $25 \mathrm{~cm}$. The crop was given $168-112-112 \mathrm{~kg}$ NPK/ha as urea, single super phosphate and potash (MOP), respectively. The crop was planted in February 2013 and harvested in early January 2014. Meteorological data for growing periods of the crop were collected from the Observatory of Plant Physiology, Agronomic Research Institute, Ayub Agricultural Research Institute, Faisalabad, Pakistan (Fig.1). All other agronomic practices and plant protection measures were applied uniformly when required during crop season. At maturity data were recorded for cane thickness $(\mathrm{cm})$, cane length $(\mathrm{cm})$, leaf area $\left(\mathrm{cm}^{2}\right)$, number of leaves per plant, number of tillers per plant, inter-nodal length $(\mathrm{cm})$, leaf margins, inter-node shape, growth habit, bud type, cane shape, trashing, cane color, Brix (\%), pol (\%), purity $(\%)$, fiber $(\%)$, commercial cane sugar (CCS\%) and sugar recovery $(\%)$.

The data were analyzed using Ward's linkage cluster analysis and principle component analysis (Ogunbayo et al., 2005). Widow operated SPSS version 12.0 was used for cluster analysis and for PCA "R language" was used. To group all studied genotypes and determine their genetic affinity, cluster analysis was performed using the squared Euclidean and Ward's method (Kumar et al., 2009). Average standardized data were used for cluster analysis, whereas, diagnosis function was used for separating the clusters of dendrogram. Cluster analysis identified variables which were further clustered into main group and subgroups. Principal component analysis simplified the complex data by transforming number of correlated variables into a smaller number of variables called principal components. The first principal component accounted for maximum variability in the data as compared to each succeeding component. Scatter diagram was plotted to show the variation pattern. Mean value of each variable was standardized prior to cluster and PCA to avoid the effects due to difference in scale.

Table 1. Pedigree of 60 sugarcane genotypes.

\begin{tabular}{|c|c|c|c|c|}
\hline Sr. & Varieties/Clones & Female & Male & ID \\
\hline 1 & CPF 247 & CP-87-1628 & CP84-1198 & $1-\mathrm{F}$ \\
\hline 2 & SPF 245 & G 6888 & - & $2-\mathrm{F}$ \\
\hline 3 & S2003-US-618 & CP -87-1628 & CP 84-1198 & $3-\mathrm{F}$ \\
\hline 4 & S2002-US-628 & US-90-1090 & CP72-1210 & $4-\mathrm{F}$ \\
\hline 5 & S2003-US-247 & CP89-879 & СР88-764 & $5-\mathrm{F}$ \\
\hline 6 & HSF 240 & CP-43-33 & CP84-1198 & $6-\mathrm{F}$ \\
\hline 7 & CPF 237 & 86P-19 & CP 70-1133 & $7-\mathrm{F}$ \\
\hline 8 & SPF 234 & SP- 71-8210 & SP -71-6180 & $8-\mathrm{F}$ \\
\hline 9 & S2003-US-718 & CP -87-1628 & CP- 84-1198 & $9-\mathrm{F}$ \\
\hline 10 & S2003-US-778 & CP -43-33 & CP -89-879 & $10-\mathrm{F}$ \\
\hline 11 & S2003-US-165 & CP $-89-879$ & CP-90-956 & $11-\mathrm{F}$ \\
\hline 12 & S2002-US-312 & CL-75-0853 & CP-86-1180 & $12-\mathrm{F}$ \\
\hline 13 & HSF 242 & SPHS- 89-2085 & CP $-89-879$ & $13-\mathrm{F}$ \\
\hline 14 & CP $-77-400$ & Introduction & - & $14-\mathrm{F}$ \\
\hline 15 & CP 72-2086 & CP 62-374 & CP 63-558 & $15-\mathrm{F}$ \\
\hline 16 & CPF 246 & US -90-1093 & CP- $81-1425$ & $16-\mathrm{F}$ \\
\hline 17 & SPF 213 & SP -70-1006 & - & $17-\mathrm{F}$ \\
\hline 18 & S2003-US-694 & CP87-1628 & CP84-1198 & $18-\mathrm{F}$ \\
\hline 19 & S2003-US-633 & CP87-1628 & CP84-1198 & $19-\mathrm{F}$ \\
\hline 20 & S2003-US-127 & CP89-879 & СР90-956 & $20-\mathrm{F}$ \\
\hline 21 & S2003-US-410 & US90-25 & НоСР85-845 & $21-\mathrm{F}$ \\
\hline 22 & S2003-US-114 & CP89-879 & СР90-956 & $22-\mathrm{F}$ \\
\hline 23 & S2002-US-133 & CP88-1561 & CP85-1491 & $23-\mathrm{F}$ \\
\hline 24 & S96-SP-302 & Co. 1148 & BL-4 & $24-\mathrm{F}$ \\
\hline 25 & S2005-US-54 & СР92-1167 & СР93-1634 & $25-\mathrm{F}$ \\
\hline 26 & CPF 235 & $86 \mathrm{P}-30$ & CP 70-1133 & $26-\mathrm{F}$ \\
\hline 27 & BF 162 & Co 1001 & - & $27-\mathrm{F}$ \\
\hline 28 & S2002-US-312 & CL75-0853 & CP86-1180 & $28-\mathrm{F}$ \\
\hline 29 & CP 43-33 & Introduction & - & $29-\mathrm{F}$ \\
\hline 30 & BL 4 & PoJ 2878 & - & $30-\mathrm{F}$ \\
\hline 31 & SPF 238 & Polly cross & CP49-34 & $31-\mathrm{F}$ \\
\hline
\end{tabular}


Cont. Table 1

\begin{tabular}{lllll}
\hline Sr. & Varieties/Clones & Female & Male & ID \\
\hline 32 & SPSG 79 & N5679 & SP70-1143 & 32-J \\
33 & SPSG 26 & SP73-5358 & SP70-1143 & 33-J \\
34 & NSG 311 & N19 & Mo/F & 34-J \\
35 & SPSG 394 & N5679 & SP70-1143 & 35-J \\
36 & HoSG 1296 & CP90-956 & RSB90-12 & 36-J \\
37 & NSG 59 & $87 F 2007$ & 77Fo790 & 37-J \\
38 & CPSG 3481 & CP85-1308 & CP81-1238 & 38-J \\
39 & CPSG 2923 & CP93-1309 & HoCP94-822 & 39-J \\
40 & CSSG 668 & $81-N 289$ & CP74-2005 & 40-J \\
41 & CSSG 676 & ROC-01 & CP74-2005 & 41-J \\
42 & CPSG 2875 & CP93-1309 & HoCP94-822 & 42-J \\
43 & CPSG 437 & CP92-1320 & CP92-1167 & 43-J \\
44 & HoSG 1257 & CP88-702 & CP86-1747 & 44-J \\
45 & HoSG 315 & CP90-956 & CP89-879 & 45-J \\
46 & CSSG 2476 & MG87-1215 & 86A-3626 & 46-J \\
47 & SL 92-5588 & CP 56 59 & Poly cross & 47-SL \\
48 & SL 95-4443 & PH 85 296 & Co 775 & 48-SL \\
49 & SL 96-771 & Co 1148 & SL 85 18 & 49-SL \\
50 & SL 89-1673 & CP 63 306 & NCO 339 & 50-SL \\
51 & SL 92-4997 & SL 7229 & Selfed & 51-SL \\
52 & SL 94-3325 & CP 77-414 & SLC 91-8 & 52-SL \\
53 & SL 96-328 & Co 1148 & Co 527 & 53-SL \\
54 & SL 96-128 & Co 775 & CP 77 414 & 54-SL \\
55 & SL 92-4918 & CP 64 103 & selfed & 55-SL \\
56 & SL 95-4432 & Co 775 & PHIL 56 59 & 56-SL \\
57 & SL 71-03 & Co 775 & SL 63 01 & 57-SL \\
58 & SL 96-278 & SLC 91 01 & CP 70 300 & 58-SL \\
59 & SL 93 945 & CP 48 103 & selfed & 59-SL \\
60 & SL 95 4033 & LF 75 10045 & PH 83 1164 & 60-SL \\
\hline
\end{tabular}

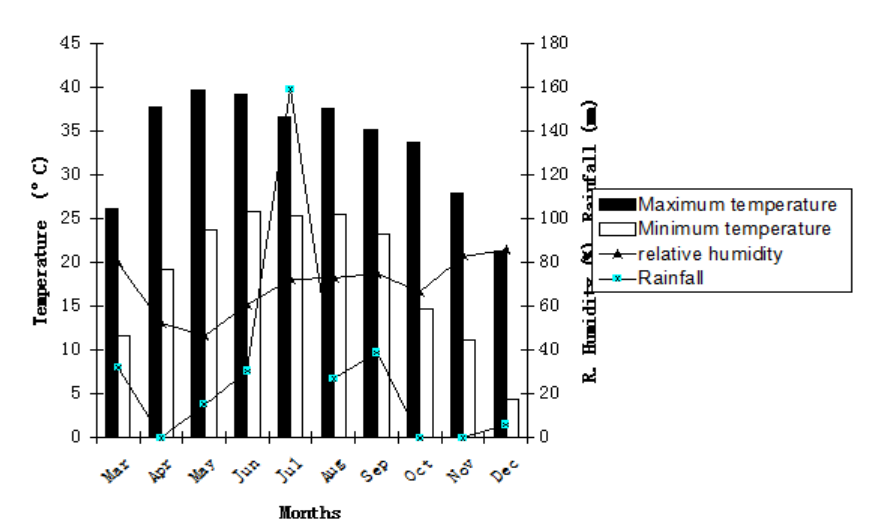

Figure 1. Meteorological data at AARI, Faisalabad, Pakistan-2013.

Data matrix of $60 \times 19$ were prepared and averages were analyzed using Ward's linkage cluster analysis (WLCA) and principal component analysis. Out of 19, 7 PCs exhibited eigen value more than one (Table $2 a$ ) and accounted about $72.1 \%$ of variability and were given due importance for further explanation.

The $\mathrm{PC}_{1}$ accounted for $19.3 \%, \mathrm{PC}_{2} 12.2 \%, \mathrm{PC}_{3} 10.9 \%, \mathrm{PC}_{4}$ $9.6 \%, \mathrm{PC}_{5} 8 \%, \mathrm{PC}_{6} 6.6 \%$ and $\mathrm{PC}_{7}$ showed $5.6 \%$ variability among genotypes for traits under study (Table $2 \mathrm{a}$ ). The most effective traits in first component $\mathrm{PC}_{1}$ were: sugar recovery, polarity, purity and CCS while number of leaves/plant, leaf area and internode length in $\mathrm{PC}_{2} . \mathrm{PC}_{1}$ was mostly related to quality parameters while $\mathrm{PC}_{2}$ morphological traits related to foliage. Brix was an effective trait in third component $\left(\mathrm{PC}_{3}\right)$ while cane diameter, bud type and trashing values showed greatest effective influence on $\mathrm{PC}_{4}$. Brix is quality controlling factor while $\mathrm{PC}_{4}$ parameters mostly related to morphological traits related to variety identification characters. $\mathrm{PC}_{5}$ was mostly related with leaf margins, growth habit and cane shape (morphological traits related to variety identification) while in $\mathrm{PC}_{6}$ most genotypes were related to cane length, tillers/plant and fiber. Overall, $\mathrm{PC}_{6}$ was closely related to yield traits. The $\mathrm{PC}_{7}$ was good in internodal shape and cane color (morphological traits related to variety identification) (Table 1b). From first seven PCs it was clear that among all the 19 variables, cane length had highest weight-age value (Table $2 b)$.

Scree plot: Scree plot explained the percentage variance associated with each principal component, obtained from the graph between eigen values and principal component numbers. The $\mathrm{PC}_{1}$ showed $19.3 \%$ variability with eigen value of 3.67 in the germplasm and gradually decreased (Table 2a). It tends to straight after $7^{\text {th }} \mathrm{PC}$, subsequent to little variance was observed in each PC. It ends at $5.3 \%$ at $7^{\text {th }} \mathrm{PC}$ with eigen value 1.005 . The graph showed $72 \%$ variation is present in first seven PCs (Fig. 2).

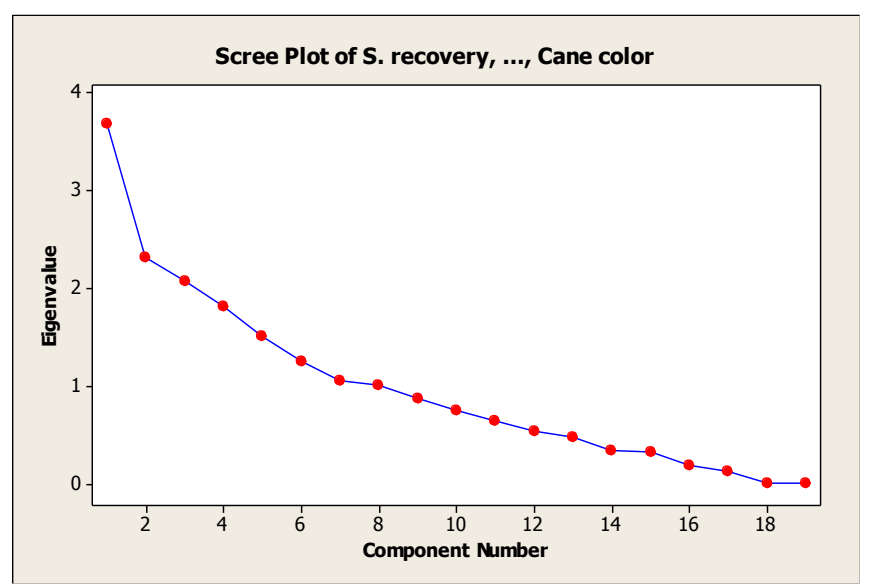

Figure 2. Scree plot analysis between eigen values and number of principal components using principal component analysis. 
Table 2b. Principal components of 60 sugarcane genotypes for 19 characters.

\begin{tabular}{lrrrrrrr}
\hline Variable & $\mathbf{P C}_{\mathbf{1}}$ & $\mathbf{P C}_{\mathbf{2}}$ & $\mathbf{P C}_{\mathbf{3}}$ & $\mathbf{P C}_{\mathbf{4}}$ & $\mathbf{P C}_{\mathbf{5}}$ & $\mathbf{P C}_{\mathbf{6}}$ & $\mathbf{P C}_{\mathbf{7}}$ \\
\hline SR & -0.492 & -0.116 & 0.006 & -0.027 & 0.117 & -0.051 & 0.056 \\
LM & -0.046 & -0.076 & 0.303 & 0.319 & -0.433 & 0.162 & -0.070 \\
NL/P & 0.200 & -0.406 & 0.023 & -0.149 & 0.199 & 0.141 & -0.069 \\
LA & 0.060 & -0.442 & -0.220 & 0.128 & -0.280 & -0.144 & 0.260 \\
CL & 0.051 & -0.065 & 0.124 & 0.203 & 0.065 & -0.597 & 0.273 \\
CD & 0.021 & -0.198 & -0.012 & -0.398 & 0.194 & -0.260 & 0.244 \\
IL & 0.147 & -0.457 & -0.119 & 0.199 & -0.165 & 0.259 & 0.154 \\
T/P & 0.007 & 0.213 & -0.127 & 0.370 & 0.028 & -0.431 & -0.213 \\
B & 0.142 & 0.131 & 0.574 & -0.133 & 0.071 & -0.045 & 0.157 \\
POL & -0.389 & -0.099 & 0.302 & -0.112 & 0.096 & 0.057 & 0.093 \\
PU & -0.402 & -0.114 & -0.382 & 0.070 & 0.039 & 0.015 & -0.072 \\
F & 0.170 & -0.320 & 0.073 & -0.017 & -0.043 & -0.376 & -0.246 \\
CCS & -0.492 & -0.116 & 0.006 & -0.027 & 0.117 & -0.050 & 0.056 \\
IS & 0.093 & 0.257 & -0.348 & -0.126 & -0.067 & -0.126 & 0.431 \\
GH & 0.179 & -0.112 & -0.153 & 0.037 & 0.451 & -0.003 & -0.381 \\
BT & 0.116 & 0.027 & -0.183 & -0.362 & 0.035 & 0.053 & -0.182 \\
CS & -0.144 & 0.126 & -0.095 & -0.182 & -0.425 & -0.170 & -0.401 \\
T & -0.016 & 0.011 & 0.041 & 0.500 & 0.430 & 0.098 & -0.006 \\
CC & 0.095 & 0.269 & -0.227 & 0.123 & 0.070 & 0.217 & 0.298 \\
\hline SR Sug
\end{tabular}

$\mathrm{SR}=$ Sugar recovery, IL=Internodal length, IS=Internode shape, $\mathrm{CC}=$ Cane color, $\mathrm{CCS}=\mathrm{Commercial}$ Cane Sugar, $\mathrm{B}=\mathrm{Brix}$, $\mathrm{GH}=$ Growth habit, $\mathrm{L} / \mathrm{P}=$ Number of leave per plant, $\mathrm{POL}=$ Polarity, $\mathrm{BT}=\mathrm{Bud}$ type, $\mathrm{LA}=\mathrm{Leaf}$ area, $\mathrm{PU}=\mathrm{Purity}, \mathrm{CS}=\mathrm{Cane}$ shape, $\mathrm{CL}=$ Cane length, $\mathrm{F}=$ Fiber, $\mathrm{T}=$ Trashing, $\mathrm{CD}=$ Cane diameter, $\mathrm{T} / \mathrm{P}=$ Tiller per plant, $\mathrm{LM}=$ Leaf margins.

Score plot: The character loading was used to calculate the accession component scores. The first two components were extracted for two dimensional ordinations of genotypes (Fig. 3). Principle component score or scatter plot depicted that the accessions that were close together, supposed to be similar when rated on the 19 variables. While accessions which were farther apart might be different from each other.

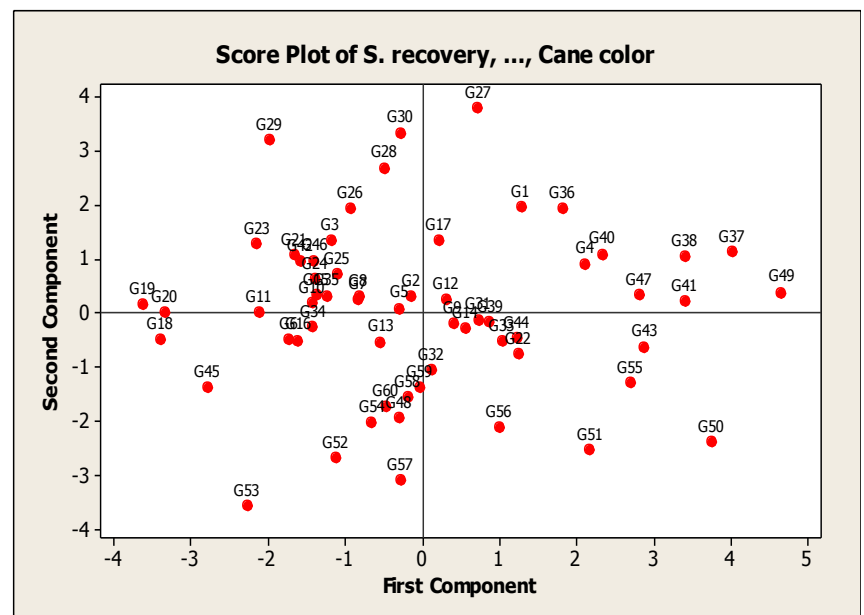

Figure 3. Two dimensional ordinations using principal component axis I and II for 60 genotypes of sugarcane.
The accessions 10-15-35, 7-8, 21-42, 33-44, 31-39, 9-14 and 4-40 were very close to each other on score plot. The accessions 27 and 53, 29 and 50, 49 and 45 were at opposite axis to each other. The accessions 52, 57, 56, 51, 55, 43 were spread on score plot at distance. The present results showed that Pakistani's genotypes were at opposite axis to Sri Lankan's on score plot (in score plot genotypes 1-31 represents the codes of SRI, FSD genotypes while 47-60 of SRI, Sri Lanka).

Loading plot: The projection traits on $\mathrm{PC}_{1}$ and $\mathrm{PC}_{2}$ revealed that length of 4 vectors (CCS, sugar recovery, number of leaves/plant and internode length) were greater than others, followed by leaf area, polarity and purity (Fig. 4).

While minimum length of vector related to leaf margins. Cane shape and growth habit were opposite to each other, and negatively correlated. Similarly, internodal shape and cane color were at opposite axis to leaf margins and showed negative association with each other (Figure 4). It may be concluded from the results of principal component analysis that characters could be grouped in 4 categories, namely: "quality related traits", "morphological traits related to foliage", "yield traits" and "morphological traits related to variety identification characters".

The results from cluster analysis were placed in 7 groups. All genotypes based on minimum variance method. 


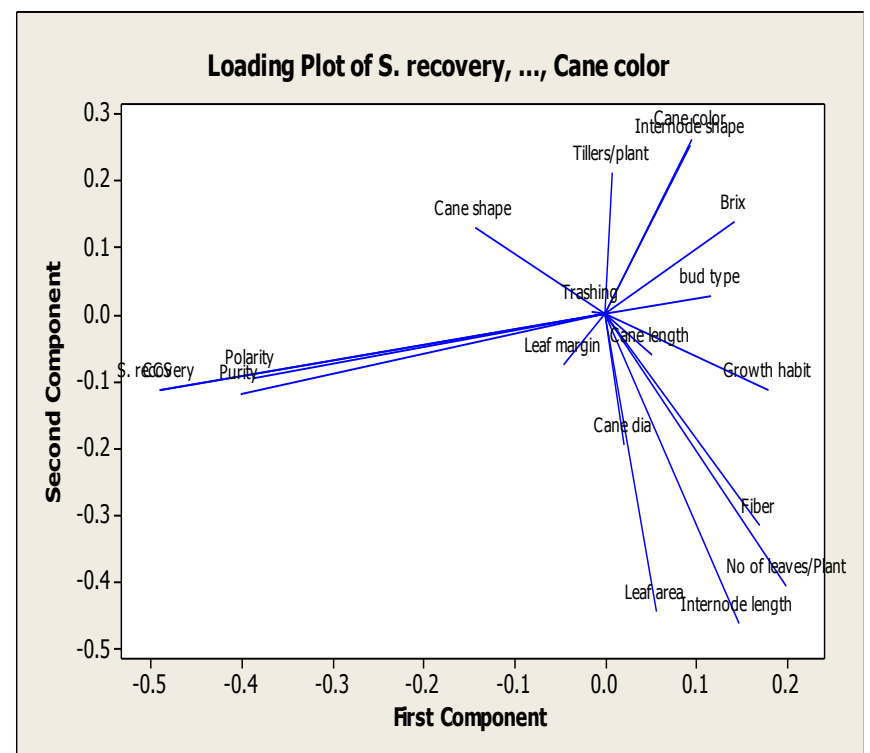

Figure 4. Loading Plot of 60 genotypes of sugarcane on Principal Component axis I and II.

Cluster I had 13 genotypes (Fig. 5) which were further divided into 3 sub-clusters $(1 \mathrm{a}, 1 \mathrm{~b}, 1 \mathrm{c})$ on the basis of similarities. This cluster belonged to genotypes from all the three stations. Accessions grouped in cluster I had highest cane diameter but lower in polarity and majority of genotypes related to ovate typed bud.

Cluster II contained 2 sub-clusters (2a, 2b) which also had 13 genotypes (Fig. 5). This cluster contained genotypes mostly belonged to SRI, FSD. Accessions grouped in cluster II had higher tillers/plant, cane length, sugar recovery, fiber and CCS. While majority of genotypes were having serrated leaf margins, medium trashing, straight cane shape and round buds.

Cluster III had 6 genotypes (Fig. 5) in 2 sub-clusters (3a, 3b) and almost all belonged to SRI, Sri Lanka. Accessions grouped in cluster III were higher in number of leaves/plant and internodal length. While majority of genotypes were bearing cylindrical shaped internodes, erect type of growth habit, medium trashing type and whitish green cane color.

Clusters IV included 6 genotypes (Fig. 5) with 2 sub-clusters (4a, 4b). 5 of them belonged to SRI, Sri Lanka. Accessions grouped in cluster IV had highest leaf area and purity but lower in Brix. Majority of genotypes were having light green cane color with semi erect growth habit.

Cluster V contained 3 sub-clusters $(5 \mathrm{a}, 5 \mathrm{~b}, 5 \mathrm{c})$ consisting of 8 genotypes (Fig. 5) belonged to SRI, FSD and SSRI, Jhang. Accessions grouped in cluster $\mathrm{V}$ had highest polarity and Brix while leaf margins were found to be serrated in majority of genotypes.
Cluster VI had 2 sub-clusters $(6 \mathrm{a}, 6 \mathrm{~b})$ which contained 11 genotypes (Fig. 5) among which 6 genotypes were from SRI, FSD while 5 genotypes were from SSRI, Jhang.

Cluster VII contained 2 sub-clusters (7a, 7b) with 3 genotypes (Fig. 5) which all belonged to SRI, FSD.

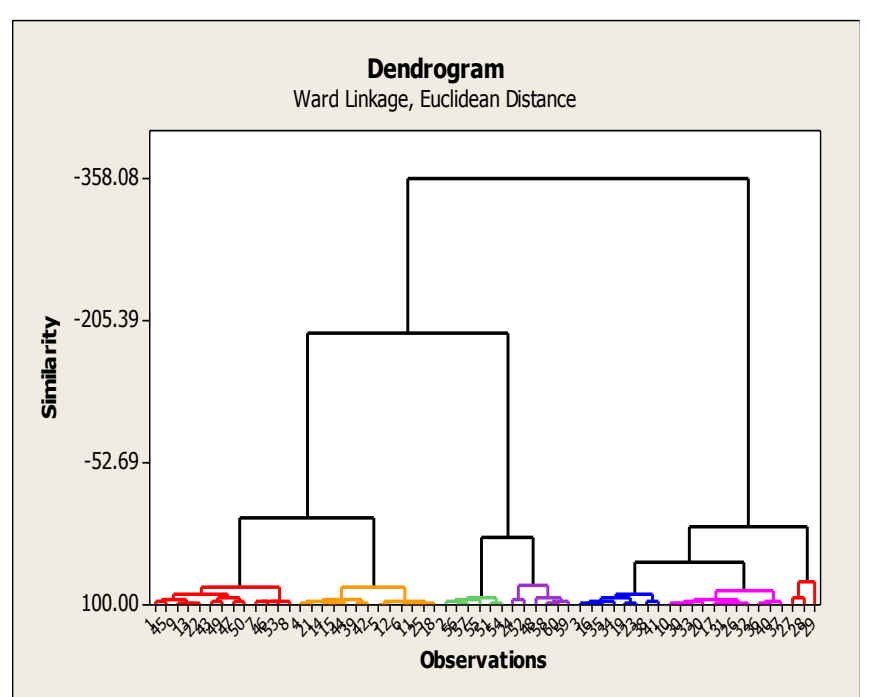

Figure 5. Dendrogram of 60 genotypes of sugarcane for 19 studied variables using Ward's Linkage method.

The germplasm contained CP, Ho, CS, SL, B, SP and N series genotypes and were grouped in same cluster irrespective of their geographical origins. Furthermore, genotypes from three stations (SRI-FSD, SSRI-Jhang and SRI-Sri Lanka) did not fall in separate clusters, rather almost each cluster was mixed with genotypes of all stations. The means and standard errors for all the clusters are given in Table 3 .

From the table of mean values and standard deviations of clusters (Table 3) it was concluded that selection of genotypes for high cane diameter could be from cluster I. Similarly for sugar recovery, cane length, tillers/plant, fiber and CCS cluster II genotypes could be preferable. For number of leaves/plant and internodal length cluster III, for leaf area and purity cluster IV and for high Brix and polarity cluster V genotypes could be selected. Maximum differences for traits were observed among clusters II and III while maximum similarity observed among clusters number. IV and VI. Mean values were also calculated of each station genotypes for each trait. Like means of all 31 genotypes of SRI, FSD for cane diameter were combined and similar was done for other two station genotypes and then trait with maximum value in particular station was written in front of that station (Table 4). So on the basis of this calculation it was concluded that SRI, FSD genotypes were higher for number of tillers per plant, 
Table 3. Means and standard errors of all seven clusters.

\begin{tabular}{lccccccc}
\hline Variable & Cluster I & Cluster II & Cluster III & Cluster IV & Cluster V & Cluster VI & ClusterVII \\
\hline SR & $11.13 \pm 1.43$ & $11.91 \pm 0.51$ & $11.09 \pm 0.97$ & $11.67 \pm 1.33$ & $11.61 \pm 0.77$ & $11.03 \pm 1.69$ & $11.02 \pm 0.77$ \\
NL/P & $13.33 \pm 1.30$ & $12.28 \pm 1.42$ & $14.33 \pm 1.22$ & $12.81 \pm 2.19$ & $13.62 \pm 1.37$ & $12.61 \pm 1.41$ & $10.30 \pm 0.90$ \\
LA & $574.74 \pm 15.16$ & $527.21 \pm 25.9$ & $629.18 \pm 11.26$ & $700.82 \pm 7.92$ & $455.73 \pm 9.07$ & $489.68 \pm 9.92$ & $372.41 \pm 70.15$ \\
CL & $2.41 \pm 0.33$ & $2.73 \pm 0.43$ & $2.57 \pm 0.48$ & $2.33 \pm 0.28$ & $2.46 \pm 0.33$ & $2.21 \pm 0.37$ & $2.03 \pm 0.50$ \\
CD & $2.68 \pm 0.21$ & $2.54 \pm 0.31$ & $2.57 \pm 0.09$ & $2.52 \pm 0.23$ & $2.51 \pm 0.15$ & $2.55 \pm 0.15$ & $2.36 \pm 0.20$ \\
IL & $16.55 \pm 5.17$ & $13.52 \pm 6.20$ & $23.38 \pm 1.16$ & $21.23 \pm 0.83$ & $13.61 \pm 5.38$ & $13.13 \pm 1.37$ & $12.87 \pm 1.70$ \\
T/P & $2.23 \pm 0.50$ & $2.53 \pm 0.21$ & $2.11 \pm 0.35$ & $2.33 \pm 0.34$ & $2.07 \pm 0.17$ & $2.24 \pm 0.23$ & $2.44 \pm 0.50$ \\
B & $19.48 \pm 1.90$ & $20.44 \pm 1.28$ & $18.18 \pm 2.09$ & $17.75 \pm 2.49$ & $21.13 \pm 2.01$ & $20.31 \pm 2.86$ & $18.76 \pm 0.90$ \\
POL & $16.45 \pm 1.36$ & $17.43 \pm 0.69$ & $16.58 \pm 1.23$ & $17.26 \pm 0.98$ & $17.81 \pm 0.34$ & $16.87 \pm 1.14$ & $16.58 \pm 1.13$ \\
PU & $84.58 \pm 8.00$ & $85.67 \pm 2.48$ & $87.25 \pm 5.28$ & $89.01 \pm 9.05$ & $82.73 \pm 6.67$ & $83.20 \pm 10.57$ & $88.24 \pm 4.08$ \\
F & $13.82 \pm 1.18$ & $14.16 \pm 0.36$ & $14.12 \pm 0.92$ & $13.45 \pm 1.22$ & $13.03 \pm 0.96$ & $13.84 \pm 0.85$ & $11.91 \pm 0.09$ \\
CCS & $11.84 \pm 1.53$ & $12.67 \pm 0.54$ & $11.79 \pm 1.03$ & $12.42 \pm 1.41$ & $12.34 \pm 0.81$ & $11.74 \pm 1.81$ & $11.72 \pm 0.82$ \\
IS & Conidial & Cylindrical & Cylindrical & Conidial & Cylindrical & Cylindrical & Conidial \\
GH & Erect & Erect & Erect & Erect & Erect & Erect & Erect \\
BT & Ovate & Round & Round & Round & Round & Round & Round \\
CS & Straight & Straight & Straight & Straight & Zigzag & Straight & Straight \\
T & Loose & Medium & Medium & Loose & Loose & Loose \\
CC & Light purple & Light purple & Whitish green & Light green & Whitish & Greenish white & Greenish purple \\
LM & Serrated & Serrated & Serrated & Serrated & Serrated & Serrated & Serrated \\
\hline
\end{tabular}

$\mathrm{SR}=$ Suger recovery, $\mathrm{IL}=$ Internodal length, $\mathrm{IS}=$ Internode shape, $\mathrm{CC}=$ Cane color, $\mathrm{CCS}=$ Commercial Cane Sugar, $\mathrm{B}=\mathrm{Brix}$, $\mathrm{GH}=$ Growth habit, $\mathrm{L} / \mathrm{P}=$ Number of leave per plant, $\mathrm{POL}=$ Polarity, $\mathrm{BT}=\mathrm{Bud}$ type, $\mathrm{LA}=$ Leaf area, $\mathrm{PU}=\mathrm{Purity}, \mathrm{CS}=\mathrm{Cane}$ shape, $\mathrm{CL}=$ Cane length, $\mathrm{F}=$ Fiber, $\mathrm{T}=$ Trashing, $\mathrm{CD}=$ Cane diameter, $\mathrm{T} / \mathrm{P}=$ Tiller per plant, $\mathrm{LM}=$ Leaf margins.

sugar recovery, purity and CCS. SSRI, Jhang genotypes were higher for number of leaves per plant, cane length, cane diameter, Brix and polarity while SRI, Sri Lanka genotypes were higher for leaf area, internodal length and fiber.

Table 4. Character selection from each station of the basis of mean values of a particular station genotypes.

\begin{tabular}{lll}
\hline Sr. No. & Characters & Region \\
\hline 1 & Number of tillers per plant & SRI, FSD \\
2 & Sugar recovery & \\
3 & Purity & \\
4 & CCS & \\
5 & Number of leaves per plant & SSRI, Jhang \\
6 & Cane length & \\
7 & Cane diameter & \\
8 & Brix & SRI, Sri Lanka \\
9 & Polarity & \\
10 & Leaf area & \\
11 & Internodal length & \\
12 & Fiber & \\
\hline
\end{tabular}

\section{DISCUSSION}

Popular genetic materials could form the breeder's initial material for developing cultivars. Characterization and accurate estimation of genetic diversity is very important in crop breeding as it helps in the selection of desirable genotypes, identifying diverse parental combination for further improvement through selection in the segregating populations (Mohammadi and Prasanna, 2003). This study evaluated the breeding worth of sugarcane source material.

The use of multivariate statistical analysis like PCA has potential to increase the comprehension of relationship among variable and could be helpful in understanding the nature of traits (Al-Sayed et al., 2012). The conducted PCA allowed the reduction of 19 primary characteristics to 7 PCs. The new trait's groups were named: quality related traits, morphological traits related to foliage, yield traits and morphological traits related to variety identification characters. Means for improvement of quality related traits, consideration could be made via traits: sugar recovery, purity, polarity, CCS and Brix for specific trait improvement or on all traits at a time for overall quality upgrading. Similar is for other 3 concluded groups. Traits fall under one variable/group could be selected for the improvement of that specific variable/group. Tahir et al. (2013) categorized the components into two groups named "Vigor, and "Quality. Deepak et al. (2012) came up with similar findings like ours and found quality traits (Brix, Pol) in first two principal components. Al-Sayed et al. (2012) found yield parameters in first 3 PCs contributing $85.3 \%$ variability contrary to our 
results which showed yield traits in $6^{\text {th }} \mathrm{PC}$. In present study first 7 PCs exhibited $72 \%$ variation. Contrary to our results Muyco (2000) found 4 principal components giving rise to $76 \%$ variation in the data. The results of loading plot/biplot indicated that sugar recovery and CCS had positive and high association with both polarity and purity and cane diameter with tillers/plant as angle between these vectors was very small (Acute, $\left\langle 90^{\circ}\right.$ ). These results contrasted to Smiullah et al. (2013) where they found that cane diameter had higher association with number of nodes. Sugarcane genotypes from Pakistan were at opposite axis on score plot to Srilankan genotypes. Similar results were obtained by Gulnaz et al. (2012) in wheat where they found Pakistani varieties were at opposite axis to CIMMYT varieties.

Cluster analysis showed that on the basis of geographical origins, there was no correspondence between clustering of genotypes. The germplasm contained genotypes of three regions and were grouped in same cluster irrespective of their geographical origin. Tahir et al. (2013) found similar findings but opposite results were found by Olaoye 1999 who found two groups of genotypes on the basis of region. This suggested that the genotypes of different regions have genetic similarity and could have been derived of same genetic material. The formation of groups is important in progenitor choice in breeding programs, since the new hybrid populations should be established on the basis of the magnitude of their dissimilarities and on the "per se" potential of the progenitors. The Ward's clustering method has permitted the formation of groups in the studies of various crops, like; sugarcane (Tahir et al., 2013; You et al., 2013; Luo et al., 2005; Ilyas et al., 2005), wheat (Khodadadi et al., 2011) and Brassica rapa (Mahmud et al., 2011). The clustering pattern of the genotypes revealed that varieties/lines originating from the same places did not form a single cluster because of direct selection pressure. This indicates that geographic diversity has not related to genetic diversity that may be due to continuous exchange of genetic materials among countries of the world. Same results had been reported by Anand and Rawat (1984) in brown mustard. Higher estimate of inter-cluster between cluster II and IV was observed which indicated wider genetic diversity between these two groups. Thus, genotypes with high index for specific character that fall into different clusters could be inter-crossed to have maximum hybrid vigor and good number of useful segregants. Hybridization of these two groups may result in transgressive recombinants for important biometric traits.

Conclusion: The findings of this study suggested 4 groups for 19 variables using PCA, named quality related traits, morphological traits related to foliage, yield traits and morphological traits related to variety identification. Cluster analysis grouped genotypes in seven groups. Group I and II contained 13 genotypes each; similarly group III and IV contained 6 genotypes each. Group V had 8, group VI 11 while group VII had 3 genotypes. Two conclusions were drawn through cluster analysis. First is genotypes falling in respective cluster could be selected for trait improvement mentioned with that specific cluster either through selection or hybridization. This was separately concluded for five clusters. Second conclusion was trait improvement for future breeding on the basis of mean values from studied genotypes for all the three mentioned stations. Four mentioned traits could be improved by selection in SRI, FSD genotypes, five in SSRI, Jhang and three in SRI, Sri Lankan genotypes.

Acknowledgments: This work was supported by Sugarcane Research Institute, AARI, Faisalabad and Shakarganj Sugar Research Institute, Jhang-Pakistan.

\section{REFERENCES}

Al-Sayed, H.M., H.S. Fateh, W.M. Fares and A.S. Attaya. 2012. Multivariate analysis of sugar yield factors in sugar cane. Amr. Eurasian J. Sustain. Agric. 6: 44-50.

Ananda, I.J. and D.S. Rawat. 1984. Genetic diversity, combining ability and heterosis in brown mustard. Ind. J. Genet. Plant Breed. 44: 226-234.

Berding, N. and B.T. Roach. 1987. Germplasm collection, maintenance and use. In: D.J. Heinz (ed.), Sugarcane Improvement through Breeding. New York, Elsevier, pp.143-210.

Brasileiro, B.P., C.D. Marinho, P.M.A. Costa, E.F.A. Moreira, L.A. Peternelli and M.H.P. Barbosa. 2013. Genetic diversity in sugarcane varieties in Brazil based on the Ward-Modified Location Model clustering strategy. Genet. Mol. Res. 13: 1650-1660.

D'Hont, A., D. Ison, K. Alix, C. Roux and C. Glaszmann. 1998. Determination of basic chromosome numbers in the genus Saccharum by physical mapping of ribosomal RNA genes. Genome 41: 221-225.

Deepak, S., R. Kishore, G.H.B. Mohammad and L. Maryke. 2012. From sugar industry to cane industry: Investigations on multivariate data analysis techniques in the identification of different high biomass sugarcane varieties. Euphytica 185: 543-558.

Fahim, M.G. 2014. Study on yield and some agronomic traits of promising genotypes and lines of bread wheat through principal component analysis. J. Biol. Environ. Sci. 2: 443-446.

Gulnaz, S., S.H. Khan, M. Shahzad, M. Ashfaq and M. Sajjad. 2012. Genetic evaluation of spring wheat (Triticum 
aestivum) germplasm for yield and seedling vigor traits. J. Agric. Soc. Sci. 8: 123-128.

Hamrick, J. 2004. Response of forest trees to global environmental change. Forest Ecol. Manage. 197: 323335.

Ilyas, M.K. 2011. Genetic variability and contribution of some morphological traits in cane yield and sucrose recovery in (Saccharum officinarum). Available online at http://agris.fao.org. AGRIS Record No. PK2004000303

Irvine, J.E. 1999. Saccharum species as horticultural classes. Theor. Appl. Genet. 98: 186-194.

Khodadadi, M., M.H. Fotokian and M. Miransari. 2011. Genetic diversity of wheat (Triticum aestivum L.) genotypes based on cluster and principal component analyses for breeding strategies. Aus. J. Crop Sci. 5: 1724.

Klomsa, A.P., A. Patanothai and P. Jaisil. 2013. Efficient test sites for multi environment evaluation of sugarcane genotypes in Thailand. Int. J. Plant Prod. 7: 763-790.

Kumar, N., U.P. Sinha and S. Paswan. 2009. Correlation and regression studies in sugarcane (Saccharum officinarum L.). Environ. Ecol. 27: 1183-1185.

Luo, J., Z. Hua and X. Liangnian. 2005. Comparison and cluster analysis of photosynthetic characters of different sugarcane varieties. Sci. Agric. Sin. 38: 1562-1569.

Mahmud, M.A.A., M.A. Syed, M.R. Mamunur, M.R. Islam and A. Husna. 2011. Genetic divergence in 58 advanced lines of Brassica rapa. Libyan Agri. Res. Center J. Int. 2: 209-214.

Mohammadi, S.A. and B.M. Prasanna. 2003. Analysis of genetic diversity in crop plants-salient statistical tools and considerations. Crop Sci. 43:1235-1248.

Mostafa, K., H. Mohammad and M. Mohammad. 2011. Genetic diversity of wheat genotype based on cluster and principal component analyses for breeding strategies. Aust. J. Crop Sci. 5: 17-24.

Muyco, R.R. 2000. Genetic diversity in sugarcane (Saccharum spp. L.) from the active germplasm collection of PHILSURIN [Philippine Sugar Research Inst.,] based on coefficient of parentage, agromorphological traits and DNA microsatellite markers,
Available online at http://agris.fao.org. AGRIS Record No. PH2003001327

Nawaz. M., I. Ullah, N. Iqbal, M.Z. Iqbal and M.A. Javed. 2013. Improving in vitro leaf disk regeneration system of sugarcane (Saccharum officinarum L.) with concurrent shoot/root induction from somatic embryos. Turk. J. Biol. 37: 726-732.

Ogunbayo, S.A., D.K. Ojo, R.G. Guei, O.O. Oyelakin and K.A. Sanni. 2005. Phylogenetic diversity and relationship among 40 rice accessions using morphlogical and RAPDs techniques. Afr. J. Biotechnol. 4: 1234-1244.

Olaoye, G. 1999. Estimating genetic divergence among local sugarcane germplasm accessions by use of principal component and cluster analyses. Nigerian J. Bot. 2: 137 143.

Pinto, L.R., A.A.F. Garcia, M.M. Pastina, L.H.M. Teixeira, J.A. Bressiani, E.C. Ulian, M.A.P. Bidoia and A.P. Souza. 2010. Analysis of genomic and functional RFLP derived markers associated with sucrose content, fiber and yield QTLs in a sugarcane (Saccharum spp.) commercial cross. Euphytica 172: 313-327.

Rana, M.K. and K.V. Bhat. 2005. RAPD markers for genetic diversity study among Indian cotton cultivars. Curr. Sci. 88: 1956-1961.

Smiullah, F.A. Khan, A. Afzal, Abdullah, U. Ijaz, and R. Iftikhar. 2013. Genetic diversity assessment in sugarcane using principal component analysis (PCA). Int. J. Modern Agric. 1:34-38.

Suman, A., K. Ali, J. Arro, A.S. Parco, C.A. Kimbeng and N. Baisakh. 2011. Molecular diversity among members of the Saccharum complex assessed using trap markers based on lignin-related genes. Bioenergy Res. 5: 197205.

Tahir, M., H. Rahman, R. Gul, A. Ali and M. Khalid. 2013. Genetic divergence in sugarcane genotypes. Am. J. Exp. Agric. 3: 102-109.

You, Q., L. Xu, Y. Zheng and Y. Que. 2013. Genetic diversity analysis of sugarcane parents in Chinese breeding program using gSSR markers. Sci. World J. doi.org/10.1155/2013/613062. 